\title{
PENGARUH MODEL LEARNING CYCLE TIPE 7E TERHADAP PEMAHAMAN KONSEP FISIKA SISWA KELAS VII SMP NEGERI 19 PALU
}

\author{
Resky Nurmalasari, Amiruddin Kade, Kamaluddin \\ Email: kykysagirlz@gmail.com \\ Program Studi Pendidikan Fisika, Jurusan Pendidikan MIPA, Universitas Tadulako, \\ Jl. Soekarno Hatta KM. 9 Kampus Bumi Tadulako Tondo Palu - Sulawesi Tengah
}

\begin{abstract}
Abstrak- Penelitian ini bertujuan untuk mengetahui ada tidaknya perbedaan pemahaman konsep fisika antara kelompok siswa yang mengikuti model learning cycle tipe 7E dengan kelompok siswa yang mengikuti model direct instruction. Sampel penelitian ini adalah siswa kelas VII SMP Negeri 19 Palu yang terdiri dari 19 orang siswa kelas eksperimen yang diajar menggunakan model learning cycle tipe 7E dan 19 orang siswa kelas kontrol yang diajar menggunakan model direct instruction. Metode yang digunakan adalah metode eksperimen kuasi dan desain yang digunakan adalah nonequivalent pretest-posttest group design. Instrumen pemahaman konsep fisika berupa tes berbentuk pilihan ganda beralasan yang telah diuji validitas dan reliabilitasnya. Hasil analisis data menunjukan bahwa nilai rata-rata pemahaman fisika siswa yang mengikuti model learning cycle tipe 7E dan direct instruction masing-masing sebesar 57,50 dan 49,08. Hasil analisis data menunjukkan bahwa kedua sampel berasal dari populasi yang homogen. Pengujian hipotesis ini dilakukan dengan menggunakan program SPSS (Statical Product and Service Solution) yang berdasarkan uji Fisher (Uji F). Pengujian hipotesis dilakukan pada taraf signifikansi $(a=$ 0,05). Hasil penelitian ini menunjukkan ada perbedaan pemahaman konsep fisika antara kelompok siswa yang mengikuti model learning cycle tipe 7E dan kelompok siswa yang mengikuti model direct instruction $(\mathrm{F}=4,595$; sig=0,039; sig<0,05).
\end{abstract}

Kata Kunci: model learning cycle tipe 7E; model direct instruction; pemahaman konsep.

\section{PENDAHULUAN}

Kegiatan pembelajaran di dalam kelas merupakan salah satu tugas utama guru sehingga pembelajaran dapat diartikan sebagai kegiatan yang ditujukan untuk pembelajaran siswa. Dalam pelaksanaan proses pembelajaran masih sering ditemui adanya kecenderungan meminimalkan keterlibatan siswa. Guru sangat mendominasi proses pembelajaran sehingga menyebabkan kecenderungan siswa lebih bersifat pasif sehingga mereka lebih banyak menunggu penjelasan dari guru jika dibandingkan mencari dan menemukan sendiri pengetahuannya.

Oleh karena itu perlu adanya suatu perubahan strategi pembelajaran dari yang berpusat pada guru (teacher centered) menjadi berpusat pada siswa (student centered). Pembelajaran berpusat pada siswa adalah pembelajaran yang lebih berpusat pada kebutuhan, minat, bakat, dan kemampuan peserta didik, sehingga pembelajaran akan lebih bermakna. Sehingga siswa dapat mengeluarkan potensi dan kemampuan yang mereka miliki. Dengan melibatkan siswa dalam proses pembelajaran siswa akan lebih mudah dalam memahami apa yang dipelajari dan siswa akan lebih mudah untuk mengingatnya.

Salah satu teori yang dapat digunakan untuk melibatkan siswa dalam proses pembelajaran adalah teori konstruktivisme. Pada teori konstruktivisme siswa dapat mengeluarkan pendapat mereka, ide-ide yang mereka punya tanpa takut berbeda dari temannya. Siswa diberikan kesempatan untuk memahami materi yang diajarkan dan mencari makna dari materi tersebut. Teori kostruktivisme menggunakan strategi berpusat pada siswa (student centered). 


\section{Jurnal Pendidikan Fisika Tadulako (JPFT)}

Vol. 1 No. 2

ISSN 23383240

Model learning cycle merupakan salah satu model pembelajaran yang menggunakan pendekatan teori konstruktivisme. Model pembelajaran ini dapat membantu untuk meningkatkan motivasi belajar siswa, dan dapat menjadikan siswa lebih aktif karena siswa memiliki peranan yang sangat penting dalam proses belajar mengajar sehingga diharapkan siswa akan lebih mudah dalam memahami konsep fisika.

Banyak versi learning cycle (pembelajaran bersiklus) bermunculan dengan fase dari tiga (3E) ke lima (5E) sampai tujuh (7E). Tipe pertama terdiri dari tiga tahap yaitu eksplorasi (exploration), pengenalan konsep (concept introduction), penerapan konsep (concept application). Selanjutnya pada tahun 1989 Biological Science Curriculum Study (BSCS) mengembangkan model pembelajaran ini dari 3 tahap menjadi 5 tahap. Tahap-tahap tersebut adalah engagement, exploration, explanation, elaboration dan evaluation [1].

Selanjutnya Eisenkraft [2] mengembangkan learning cycle menjadi 7 tahapan, perubahan yang terjadi pada tahapan siklus belajar $5 \mathrm{E}$ menjadi 7E terjadi pada fase engagement menjadi 2 tahapan yaitu Elicit dan Engage, sedangkan pada tahapan Elaborate Evaluate menjadi 3 tahapan yaitu menjadi Elaborate, Evaluate dan Extend.

Menurut Hulse, Egeth dan Deese definisi konsep adalah sekumpulan atau seperangkat sifat yang dihubungkan oleh aturan-aturan tertentu atau konsep merupakan bayangan mental, ide dan proses. Walgito mengemukakan bahwa konsep merupakan konstruksi simbolik yang menggambarkan ciri-ciri suatu objek atau kejadian. Pembentukan konsep merupakan suatu proses dimana siswa dituntut untuk menentukan dasar terhadap apa yang akan mereka gunakan untuk membangun kategori-kategori atau pembentukan konsep merupakan ketajaman berfikir dalam mengklsifikasikan objek atau ide. Pemahaman sangat relevan bila kita tinjau dari sudut pandang fisika. Fisika bukan hanya sebagai kumpulan pengetahuan yang tersusun secara sistematik tetapi juga yang terpenting sebagai suatu proses. Perubahan konsep sangat penting dimiliki oleh siswa yang telah mengalami proses belajar. Pemahaman konsep yang dimiliki oleh siswa dapat digunakan untuk menyelesaikan suatu permasalahan yang ada kaitannya dengan konsep yang dimilki. Dalam pemahaman konsep siswa tidak terbatas hanya mengenal tetapi siswa harus dapat menghubungkan antara satu konsep dengan konsep lainnya [3].

Model learning cycle dapat meningkatkan pemahaman siswa hal ini dapat dilihat dari tahapannya. Tahapan pada model pembelajaran ini dapat mengukur beberapa aspek pada ranah kognitif Bloom diantaranya adalah C2 (memahami), C3 (Menerapkan) dan C4 (menganalisis) sehingga akan dapat meningkatkan pemahaman konsep siswa.

Oleh karena itu, peneliti ingin melakukan penelitian untuk mengetahui ada tidaknya perbedaan pemahaman konsep fisika antara kelompok siswa yang mengikuti model Pembelajaran Learning Cycle tipe 7E dengan kelompok siswa yang mengikuti model pembelajaran langsung.

\section{METODELOGI}

Jenis penelitian yang digunakan adalah jenis penelitian eksperimen kuasi. Adapun populasi pada penelitian ini adalah seluruh siswa kelas VII SMP Negeri 19 Palu tahun ajaran 2013/2014 yang tersebar dalam 4 kelas. Kelas VII A sebagai kelas kontrol yang siswanya mengikuti model direct instruction dan kelas VII B sebagai kelas eksperimen yang siswanya mengikuti model learning cycle tipe 7E.

Pengambilan sampel pada penelitian ini adalah purposive sampling, yaitu teknik penentuan sampel dengan pertimbangan tertentu dari guru mata pelajaran fisika pada kedua kelas di sekolah tersebut. Kedua kelas yang dipilih merupakan kelas yang dianggap homogen secara akademik. [4] 


\section{Jurnal Pendidikan Fisika Tadulako (JPFT)}

Vol. 1 No.2

Data yang diambil dari penelitian ini yaitu pemahaman konsep fisika siswa berupa tes yang diberikan pada awal dan akhir perlakuan. Desain penelitian yang digunakan seperti pada Tabel 1 .

TABEL 1. NONEQUIVALENT PRETEST-POSTTEST GROUP DESIGN

\begin{tabular}{|l|c|c|c|}
\hline \multicolumn{1}{|c|}{ Kelas } & $\begin{array}{c}\text { Tes } \\
\text { Awal }\end{array}$ & Perlakuan & $\begin{array}{c}\text { Tes } \\
\text { Akhir }\end{array}$ \\
\hline $\begin{array}{l}\text { Kelas Eksperimen } \\
(\mathrm{KE})\end{array}$ & $\mathrm{O} 1$ & $\mathrm{X}$ & $\mathrm{O} 2$ \\
\hline Kelas Kontrol (KK) & $\mathrm{O} 1$ & - & $\mathrm{O} 2$ \\
\hline
\end{tabular}

Keterangan:

KE : Kelas Eksperimen

KK : Kelas Kontrol

O1 : Tes Awal (Pretest)

O2 : Tes Akhir (Posttest)

$X \quad$ : Perlakuan menggunakan Model Learning Cycle tipe 7E

\section{HASIL DAN PEMBAHASAN}

Nilai pemahaman konsep fisika siswa diperoleh dari hasil pretest dan posttest yang dilakukan pada kedua kelas tersebut. Data hasil pemahaman konsep fisika siswa yang diperoleh seperti pada Tabel 2.

TABEL 2. SKOR PRETEST DAN POSTTEST KELAS KONTROL DAN KELAS EKSPERIMEN

\begin{tabular}{|l|c|c|c|c|}
\hline \multirow{2}{*}{ Nilai } & \multicolumn{2}{|c|}{ Kelas Kontrol } & \multicolumn{2}{c|}{ Kelas Eksperimen } \\
\cline { 2 - 5 } & Pretest & Posttest & Pretest & Posttest \\
\hline Maksimum & 100 & 100 & 100 & 100 \\
\hline Tertinggi & 25,00 & 70,00 & 25,00 & 80,00 \\
\hline Terendah & 5,00 & 35,00 & 5,00 & 30,00 \\
\hline Rata-Rata & 15,26 & 49,08 & 15,79 & 57,50 \\
\hline
\end{tabular}

$$
\text { Pengujian dilakukan dengan }
$$

menggunakan program SPSS (Statical Product and Service Solution). Uji yang dilakukan adalah uji normalitas, uji homogenitas dan uji hipotesis. Hasil uji normalitas posttest yang diperoleh seperti pada Tabel 3. Hasil uji homogenitas posttest yang diperoleh seperti pada Tabel 4. Hasil uji hipotesis posttest yang diperoleh seperti pada Tabel 5.

TABEL 3. UJI NORMALITAS POSTTEST KELAS KONTROL DAN KELAS EKSPERIMEN

\section{Tests of Normality}

ISSN 23383240

\begin{tabular}{|c|c|c|c|c|}
\hline & \multirow{2}{*}{$\begin{array}{l}\text { Model_Pembelaj } \\
\text { aran }\end{array}$} & \multicolumn{3}{|c|}{ Shapiro-Wilk } \\
\hline & & Statistic & Df & Sig. \\
\hline \multirow{2}{*}{$\begin{array}{l}\text { Nilai_Pem } \\
\text { ahaman_ } \\
\text { Konsep }\end{array}$} & Pemb_Langsung & .945 & 19 & .330 \\
\hline & LC_7E & .966 & 19 & .685 \\
\hline
\end{tabular}

Pada data uji normalitas posttest kelas kontrol memiliki sig. $=0,330$ dan pada kelas ekperimen sig. $=0,685$. Kedua kelas memiliki sig. $>0,05$, oleh karena itu data terdistribusi normal.

TABEL 4. UJI HOMOGENITAS POSTTEST KELAS KONTROL DAN KELAS EKSPERIMEN

Levene's Test of Equality of Error Variances ${ }^{a}$

Dependent Variable:Nilai_Pemahaman_Konsep

\begin{tabular}{|l|l|l|l|}
\hline$F$ & df1 & df2 & Sig. \\
\hline 1.682 & 1 & 36 & .203 \\
\hline
\end{tabular}

Tests the null hypothesis that the error variance of the dependent variable is equal across groups.

a. Design: Intercept + Model_Pembelajaran

Hasil uji homogenitas posttest kelas kontrol dan eksperimen sig. $=0,203$. Hasil dari kedua data tersebut memiliki sig. $>0,05$, maka kedua varians kelompok data sama (homogen).

TABEL 5. UJI HIPOTESIS POSTTEST KELAS KONTROL DAN KELAS EKSPERIMEN

\section{Tests of Between-Subjects Effects}

Dependent Variable:Nilai_Pemahaman_Konsep

\begin{tabular}{|r|r|r|r|r|r|}
\hline Source & $\begin{array}{r}\text { Type III Sum } \\
\text { of Squares }\end{array}$ & df & Mean Square & $\mathrm{F}$ & Sig. \\
\hline $\begin{array}{r}\text { Corrected } \\
\text { Model }\end{array}$ & $673.684^{\mathrm{a}}$ & 1 & 673.684 & 4.595 & .039 \\
\hline $\begin{array}{r}\text { Intercept } \\
\text { Model_Pembel } \\
\text { ajaran }\end{array}$ & 107911.184 & 1 & 107911.184 & 736.088 & .000 \\
\hline Error & 5277.632 & 36 & 146.601 & & \\
\hline $\begin{array}{r}\text { Total } \\
\text { Total }\end{array}$ & 113862.500 & 38 & & & \\
\hline $\begin{array}{r}\text { Corrected } \\
\text { Total }\end{array}$ & 5951.316 & 37 & & & \\
\hline
\end{tabular}

a. R Squared $=.113$ (Adjusted R Squared $=.089$ ) 


\section{Jurnal Pendidikan Fisika Tadulako (JPFT)}

Vol. 1 No.2

ISSN 23383240

Hasil uji hipotesis posttest kelas kontrol dan eksperimen pada model pembelajaran menunjukkan sig. $=0,039$. Nilai sig. $<0,05$ maka $\mathrm{H}_{0}$ ditolak atau $\mathrm{H}_{1}$ diterima. Sehingga dapat disimpulkan bahwa terdapat perbedaan pemahaman konsep fisika antara kelas yang menggunakan model learning cycle tipe 7E dan kelas yang menggunakan model direct instruction.

Pada penelitian ini, kegiatan pembelajaran dilakukan sebanyak 5 kali pertemuan terdiri dari 3 kali tatap muka dan 2 kali pertemuan untuk pemberian pretest dan posttest pada kelas eksperimen dan kelas kontrol. Penelitian ini menggunakan 2 model pembelajaran, yaitu model pembelajaran learning cycle tipe $7 E$ pada kelas eksperimen (VII B) dan model pembelajaran langsung pada kelas kontrol (VII A).

Analisis data posttest untuk menentukan apakah ada perbedaan pemahaman konsep fisika antara kelas yang menggunakan model pembelajaran learning cycle tipe 7E dan model pembelajaran langsung. Pada pengujian normalitas data kelas kontrol dan eksperimen diperoleh bahwa kedua data terdistribusi normal. Hasil uji homogenitas pada kedua data adalah varians kedua kelompok homogen. Pada uji hipotesis diperoleh bahwa hipotesis 1 atau $\mathrm{H}_{0}$ ditolak dan hipotesis $2\left(\mathrm{H}_{1}\right)$ diterima. Artinya terdapat perbedaan pemahaman konsep fisika antara kelas yang menggunakan model Learning cycle tipe 7E dan model pembelajaran langsung. Siswa pada kelas eksperimen memiliki rata-rata nilai lebih tinggi dibandingkan siswa pada kelas kontrol.

Ada perbedaan pemahaman konsep fisika pada keles eksperimen dan kontrol disebabkan oleh tahapan pembelajaran (fase pembelajaran). Ada 7 fase pembelajaran pada learning cycle yaitu, Elicit, Engage, Explore, Explain, Elaborate, Evaluate, Extend.

Fase pertama yaitu Elicit bertujuan untuk merangang pengetahuan awal siswa dengan memberikan pertanyaan yang berhubungan dengan materi yang akan dipelajari. Pada fase ini siswa mulai aktif dalam menjawab pertanyaan yang diberikan. Hal ini dapat terlihat dari antusias semua siswa dalam menjawab. Fase kedua yaitu Engage yang bertujun untuk memberitahu rencana pembelajaran atau tujuan pembelajaran dan saling bertukar pengalaman atau kejadian yang pernah dialami oleh siswa. Pada fase ini siswa mulai tertarik untuk mempelajari materi yang akan dipelajari. Siswa cenderung aktif untuk menceritakan peristiwa yang pernah mereka alami atau dari pengalaman mereka. Hal ini akan lebih memudahkan kita untuk melanjutkan ke fase selanjutnya yaitu fase Explore. Fase Explore bertujuan untuk memberikan kesempatan kepada siswa untuk menyelidiki sendiri atau melakukan eksperimen sederhana. Pada fase ini siswa akan berkelompok untuk melakukan ekperimen sederhana dan mulai menyelidiki konsep yang berhubungan dengan hal yang sedang dipelajari. Siswa menjadi lebih aktif dan guru hanya mengarahkan siswa untuk dapat menemukan konsep yang dimaksud dengan memberikan pertanyaan-pertanyaan agar siswa menjadi lebih mengerti. Fase selanjutnya adalah fase Explain yang bertujuan untuk menjelaskan. pada fase ini siswa akan memberikan perwakilan dari setiap kelompok untuk maju mempresentasikan hasil yang diperoleh pada fase Explore. Siswa akan menjelaskan konsep yang peroleh dari ekperimen sederhana yang telah dilakukan dengan menggunakan bahasa mereka sendiri atau bahasa yang mereka pahami. Guru akan meluruskan jawaban siswa. Fase yang kelima yaitu Elaborate yang bertujuan agar siswa dapat menerapkan konsep yang baru saja mereka pelajari. Pada fase ini siswa akan mengerjakan LKS (Lembar Kerja Siswa) secara berkelompok. Siswa akan lebih mudah dalam mengerjakan LKS karena mereka telah mengetahui konsep yang dipelajari. Selain itu, siswa akan mengetahui contoh penerapan dari konsep yang telah dipelajari. Fase selanjutnya adalah fase evaluate, pada ini siswa diuji dengan beberapa pertanyaan 


\section{Jurnal Pendidikan Fisika Tadulako (JPFT)}

Vol. 1 No.2

ISSN 23383240

spontan yang diberikan oleh guru. Fase yang terakhir adalah extend, pada fase ini pengetahuan siswa akan diperluas dengan mencari contoh penerapan konsep pada kehidupan sehari-hari.

Hasil perhitungan statistik yang telah dilakukan dapat disimpulkan bahwa penggunaan model pembelajaran learning cycle tipe TE dapat meningkatkan pemahaman konsep fisika siswa. Hal ini dapat ditunjukkan dari nilai yang diperoleh siswa. Siswa pada kelas eksperimen memiliki rata-rata nilai yang lebih tinggi dibandingkan nilai pada siswa di kelas kontrol. Hasil yang diperoleh sama dengan hasil penelitian yang dilakukan oleh Ni Putu Sri Ratna Dewi [5] yaitu terdapat perbedaan pemahaman konsep dan keterampilan proses antara kelompok siswa yang dibelajarkan dengan siklus belajar 7E dan siswa yang dibelajarkan dengan model pembelajaran langsung. Mabsuthoh [6] mengemukakan bahwa terdapat pengaruh penerapan model pembelajaran Learning cycle terhadap hasil belajar fisika siswa. Hasil penelitian yang dilakukan oleh Hartono [7] adalah penerapan model learning cycle tipe $7 E$ dapat meningkatkan kemampuan berpikir kritis. Begitupun menurut Simatuang [8] penggunaan model pembelajaran Learning cycle dapat mempermudah belajar siswa karena mereka secara langsung berinteraksi dengan lingkungan untuk menganalisis fenomena-fenomena perilaku sosial sehingga mereka dapat memahami konsep-konsep materi ajar sehingga tujuan pengajaran dapat tercapai.

Kelebihan dari model pembelajaran ini dibandingkan dengan model pembelajaran langsung adalah keaktifan siswa. Karena dengan menggunakan model Laerning Cycle tipe 7E siswa memiliki kesempatan untuk menyelidiki sendiri, menemukan konsep, dan menjelaskan konsep dengan bahasa yang lebih mereka pahami. Selain memiliki kelebihan model ini juga memiliki kekurangan yaitu waktu pembelajaran. Waktu pembelajaran yang dibutuhkan cenderung lebih banyak karena banyaknya fase atau langkah yang harus dilakukan. Selain itu, kita juga butuh kesabaran yang lebih dalam membimbing siswa agar dapat fokus dalam melakukan kegiatan pembelajaran.

\section{KESIMPULAN}

(1) Rata-rata nilai pemahaman konsep fisika untuk pretest pada kelas kontrol adalah 15,26 dan pada kelas ekperimen adalah 15,79 .

(2) Rata-rata nilai pemahaman konsep fisika untuk posttest pada kelas kontrol adalah 49,08 dan pada kelas eksperimen adalah 57,50 .

(3) Signifikansi yang diperoleh pada uji hipotesis adalah 0,039 atau $\mathrm{HO}$ ditolak sehingga terdapat perbedaan pemahaman konsp fisika antara kelompok siswa yang mengikuti model pembelajaran learning cycle tipe 7E dengan kelompok siswa yang mengikuti model pembelajaran langsung.

\section{DAFTAR RUJUKAN}

[1] Hardiansyah, D. (2010). Penerapan model learning cycle tipe 7E untuk meningkatkan keterampilan berpikir kritis dan penguasaan konsep siswa SMA. Skripsi pada FPMIPA Universitas Pendidikan Indonesia Bandung: tidak diterbitkan.

[2] Eisenkraft. A. (2003). "Expanding the 5E Model". Journal of National Science Teachers Association (NSTA). Vol. 70, (6), Hal. 56-59.

[3] Suciyati. (2011). Pengaruh Pemberian Tugas Konseptual dengan Model Model Pembelajaran Investigasi Kelompok Terhadap Pemahaman Konsep Fisika Siswa kelas VIII SMP Negeri 20 Palu. Skripsi pada FKIP Universitas Tadulako Palu: tidak diterbitkan.

[4] Sugiyono. (2010). Metode Penelitian Pendidikan. Bandung: PT. Alfabeta.

[5] Dewi, N.P.S. (2012). Pengaruh Model Siklus Belajar 7E Terhadap Pemahaman Konsep dan Keterampilan Proses Siswa SMA Negeri 1 Sawan. Artikel Tesis pada Program Pascasarjana Universitas pendidikan Ganesha, Bali: tidak diterbitkan

[6] Mabsuthoh, N. (2010). Pengaruh Model learning cycle Terhadap Hasil Belajar Fisika Pada konsep Massa Jenis. 
Skripsi pada FITK Universitas Islam Negeri (UIN) Syarif Hidayatullah Jakarta: tidak diterbitkan.

[7] Hartono. (2012). "Learning Cycle-7E model to Increase Student's critical Thinking on Science". Jurnal Pendidikan Fisika Indonesia (JPFI). Vol 9, hal 58-66.

[8] Simatupang, D. (2008). Pembelajaran Model Siklus Belajar (Learning cycle). Jurnal Kewarganegaraan vol $10(1)$ hal $62-70$. 